Bangladesh J. Bot. 47(4): 993-1000, 2018 (December)

\title{
EFFECTS OF ALUMINIUM STRESS ON THE ACCUMULATION OF CATIONS AND ANIONS IN RICE AND CHICKPEA SEEDLINGS GROWN IN SOLUTION CULTURE
}

\author{
Rifat Samad*, Parveen Rashid and JL Karmoker \\ Department of Botany, University of Dhaka, Dhaka-1000, Bangladesh
}

Keywords: Aluminium stress, Ion transport, Cation, Anion, Rice, Chickpea

\begin{abstract}
Different concentrations of aluminium (10-150 $\mu \mathrm{M})$ inhibited the accumulation of $\mathrm{Ca}^{2+}, \mathrm{Mg}^{2+}, \mathrm{Fe}^{2+}$ and $\mathrm{PO}_{4}{ }^{3-}$ in rice and chickpea seedlings grown in solution culture. In rice and chickpea, the intensity of inhibition of the accumulation of $\mathrm{Ca}^{2+}, \mathrm{Mg}^{2+}, \mathrm{Fe}^{2+}$ and $\mathrm{PO}_{4}{ }^{3-}$ enhanced with the increase in $\mathrm{Al}$ concentrations from 10 to $150 \mu \mathrm{M}$. On the contrary, application of aluminium caused a dramatic few fold increase in accumulation of $\mathrm{Al}^{3+}$ in different parts of rice and chickpea seedlings.
\end{abstract}

\section{Introduction}

A large amount of aluminium (Al) is incorporated into aluminosilicate soil minerals, and very small quantities appear in the soluble form, capable of influencing biological systems (May and Nordstrom 1991). Acid soil having pH below 5.0 increases the solubility of Al, which in subsoil is particularly harmful for plants (Lidon and Barreiro 2002). Nutritional imbalances induced by Al exposure were reported for several plant species (Silva 2012).

Concentration of calcium drastically reduced in presence of aluminium in spinach (Karimaei and Poozesh 2016) and cacao (Ribeiro et al. 2013). Aluminium decreased $\mathrm{Mg}^{2+}$ content in the leaves and roots of physic nut (Steiner et al. 2012) and the foliage and root of silver birch (Bojarczuk et al. 2006). Toxic Al concentration decreased significantly the concentrations of $\mathrm{Fe}^{2+}$ in sorghum (Clark et al. 1981) and in maize (Lidon et al. 1999). Al caused a decrease in Mg and Fe content in the root but an increase in those ions in the stem of Pinus massoniana was found (Zhang et al. 2014).

Exposure of $\mathrm{Al}$ increased $\mathrm{Al}^{3+}$ concentration in leaves of buckwheat (Ma et al. 1998). Concentration of $\mathrm{Al}^{3+}$ was high in the root and generally low in the tops of honeylocust and loblolly pine seedling (Wagatsuma et al. 1987). Phosphate $\left(\mathrm{PO}_{4}{ }^{3-}\right)$ uptake was first inhibited and then increased in corn root following aluminium treatment (Facanha and Okorokova-Facanha 2002). Aluminium ions blocked $P$ uptake in soybean plants (Zheng 2010).

\section{Materials and Methods}

Rice (Oryza sativa var. BRRI Dhan-53), the main cereal grain of the family Poaceae and chickpea (Cicer arietinum var. Bari chhola-7), the third most important pulse of the family Fabaceae; were used as experimental plant materials. Seeds of rice were collected from Bangladesh Rice Research Institute (BRRI) and that of chickpea were obtained from Bangladesh Agricultural Research Institute (BARI), respectively.

The seeds were surface sterilized according to Samad and Karmoker (2013). The sterilized seeds were spread over a cotton gauge placed in a lid having holes $(1 \mathrm{~cm}$ in diameter) and the lid with seeds was placed on a beaker containing $500 \mathrm{ml}$ of distilled water. The beakers were covered by black plastic sheet to avoid the exposure of light to the roots.

*Author for correspondence: <rifatsamad@gmail.com>. 
After germination, the seedlings were transferred to modified half-strength Hoagland solution (Hoagland and Arnon 1950) and the beakers with the seedlings were placed in a light bank. Rice seedlings were grown at a day/night temperature of $30 \pm 1{ }^{\circ} \mathrm{C} / 25 \pm 1{ }^{\circ} \mathrm{C}$ and day/night length of 14 $\mathrm{hrs} / 10 \mathrm{hrs}$. Chickpea seedlings were grown at a day/night temperature of $25 \pm 1{ }^{\circ} \mathrm{C} / 18 \pm 1^{\circ} \mathrm{C}$ and day/night length of $10 \mathrm{hrs} / 14 \mathrm{hrs}$. Light intensity was $160 \mu$-einstein $\mathrm{m}^{-2} \mathrm{~s}^{-1}$. The solution was continuously aerated through bubbler with the help of air compressor (Rockyvac 320). The solution was replenished every $48 \mathrm{hrs}$. Seven-day-old seedlings were transferred to half strength Hoagland solution as control and $10,50,100$ and $150 \mu \mathrm{M} \mathrm{AlCl}_{3}$ solution made in half strength Hoagland solution were used as treatments. The $\mathrm{pH}$ of all solutions including control were adjusted to 4.2 with $0.2 \mathrm{~N} \mathrm{H}_{2} \mathrm{SO}_{4}$.

$\mathrm{Ca}^{2+}, \mathrm{Mg}^{2+} \mathrm{Fe}^{2+}, \mathrm{Al}^{3+}$ and $\mathrm{PO}_{4}{ }^{3-}$ were extracted by digestion in a mixture of nitric and perchloric acid (4:1) using a hot sand bath. The amount of $\mathrm{Ca}^{2+}, \mathrm{Mg}^{2+}$ and $\mathrm{Fe}^{2+}$ in the extract were determined by an atomic absorption spectrophotometer (Perkin-Elmer, Model: AAnalyst 200) at wavelengths of $422.67,285.21$ and $248.33 \mathrm{~nm}$, respectively. $\mathrm{Al}^{3+}$ content was measured by using an atomic absorption spectrophotometer (Shimadzu, Model: AA 7000, Japan). Phosphate was measured by Vanadomolybdate method (Jackson 1967) from the aliquot obtained by digesting the plant material.

In this paper, the effect of aluminium toxicity on the accumulation and distribution of divalent and trivalent cations $\left(\mathrm{Ca}^{2+}, \mathrm{Mg}^{2+} \mathrm{Fe}^{2+}, \mathrm{Al}^{3+}\right)$ and anion $\left(\mathrm{PO}_{4}^{3-}\right)$ is reported.

\section{Results and Discussion}

The highest inhibition of $\mathrm{Ca}^{2+}$ accumulation in the root was observed at $150 \mu \mathrm{M} \mathrm{Al}$ treatment which ranged from 54.0 to $65.7 \%$ from 3 to $96 \mathrm{hrs}$ of application (Fig. 1a). In the shoot of rice the inhibitory effect of $\mathrm{Al}$ on $\mathrm{Ca}^{2+}$ accumulation increased with the increase in $\mathrm{Al}$ concentration from 10 to $150 \mu \mathrm{M}$ from 3 to $96 \mathrm{hrs}$ of $\mathrm{Al}$ exposure (Fig. 1b). In chickpea seedlings, $\mathrm{Al}$ also caused an inhibition of $\mathrm{Ca}^{2+}$ accumulation in the root, stem and leaves from 3 to $96 \mathrm{hrs}$ of treatment. (Figs 2a-c). Exposure of chickpea seedlings to $150 \mu \mathrm{M} \mathrm{Al}$ resulted in the maximum 36.0 to $57.8 \%$ inhibition of $\mathrm{Ca}^{2+}$ content in the leaves from 3 to $96 \mathrm{hrs}$ of application (Fig. 2c). This result is in agreement with the work of Zheng et al. (2005) who found that $\mathrm{Ca}^{2+}$ accumulation decreased progressively in the root of buckwheat with the increase in $\mathrm{Al}$ concentrations.
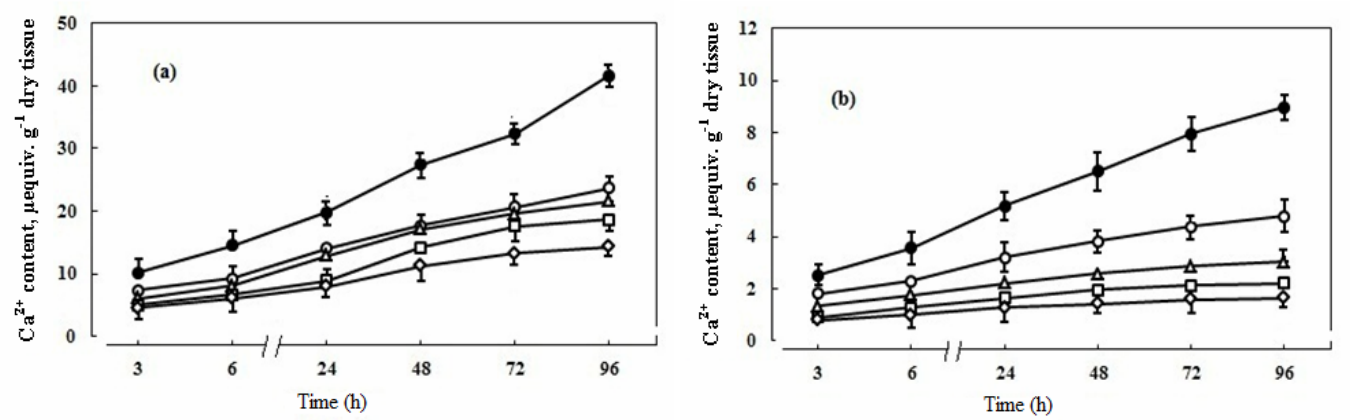

Fig. 1. The effect of different concentrations of aluminium on the accumulation of $\mathrm{Ca}^{2+}$ in the (a) root and (b) shoot of rice seedlings grown in solution culture. $\bullet$ represents control; $\circ 10 \mu \mathrm{M} \mathrm{Al} ; \Delta 50 \mu \mathrm{M} \mathrm{Al}$; $\square 100 \mu \mathrm{M} \mathrm{Al}$ and $\diamond 150 \mu \mathrm{M} \mathrm{Al}$. Each value is the mean of three replicates \pm standard error. 

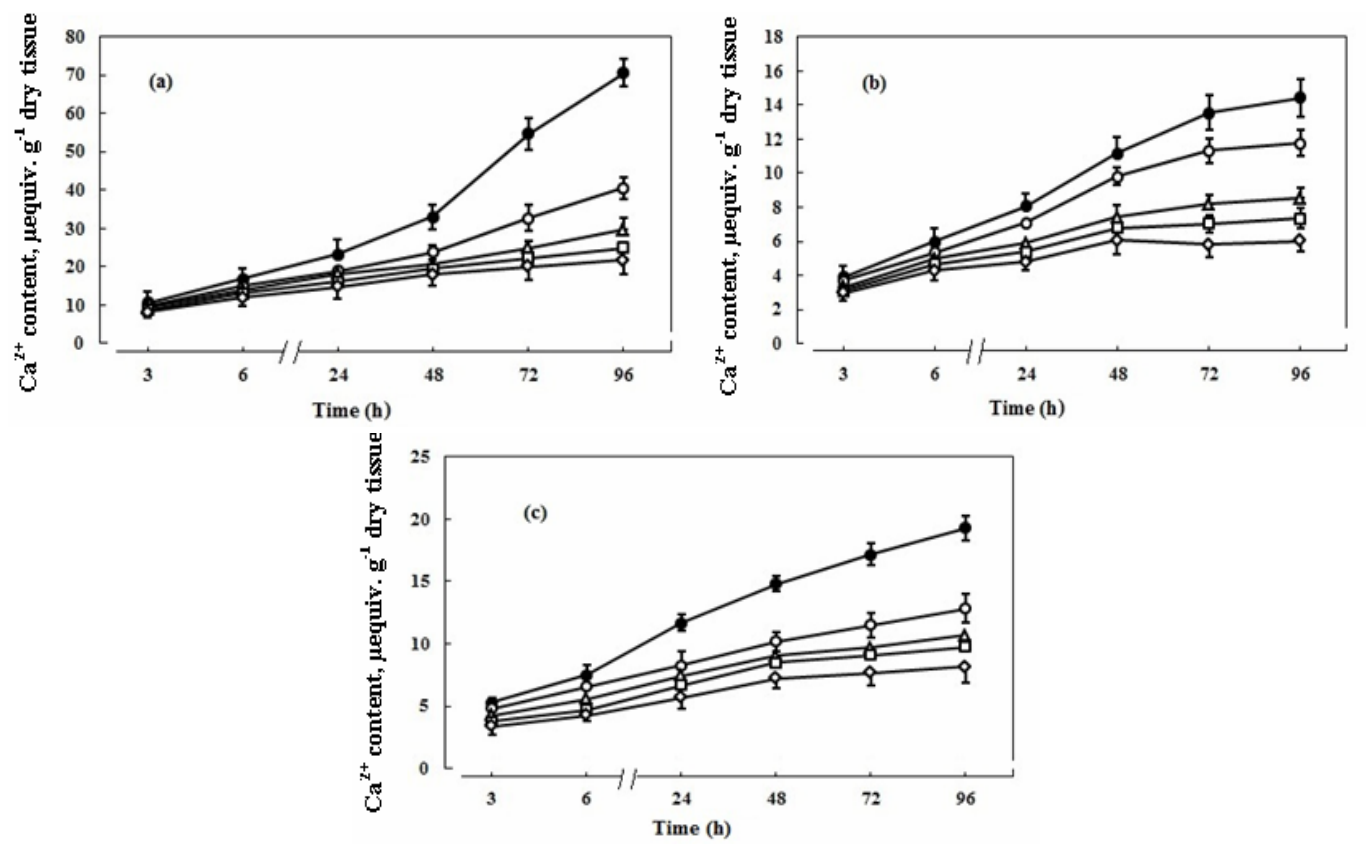

Fig. 2. The effect of different concentrations of aluminium on the accumulation $\mathrm{Cf}^{2+}$ in the (a) root,

(b) stem and (c) leaves of chickpea seedlings grown in solution culture. Otherwise as Fig. 1.

Exposure of roots of rice seedlings to $10 \mu \mathrm{M} \mathrm{Al}$ caused a 18.0 to $30.0 \%$ inhibition of $\mathrm{Mg}^{2+}$ content from 3 to $96 \mathrm{hrs}$ of treatment (Fig. 3a). Al, at concentrations of 100 and $150 \mu \mathrm{M}$, resulted in a 44.6 to $59.0 \%$ and 57.8 to $69 \%$ inhibition of $\mathrm{Mg}^{2+}$ content in the shoot respectively, from 3 to $96 \mathrm{hrs}$ of application (Fig. 3b).
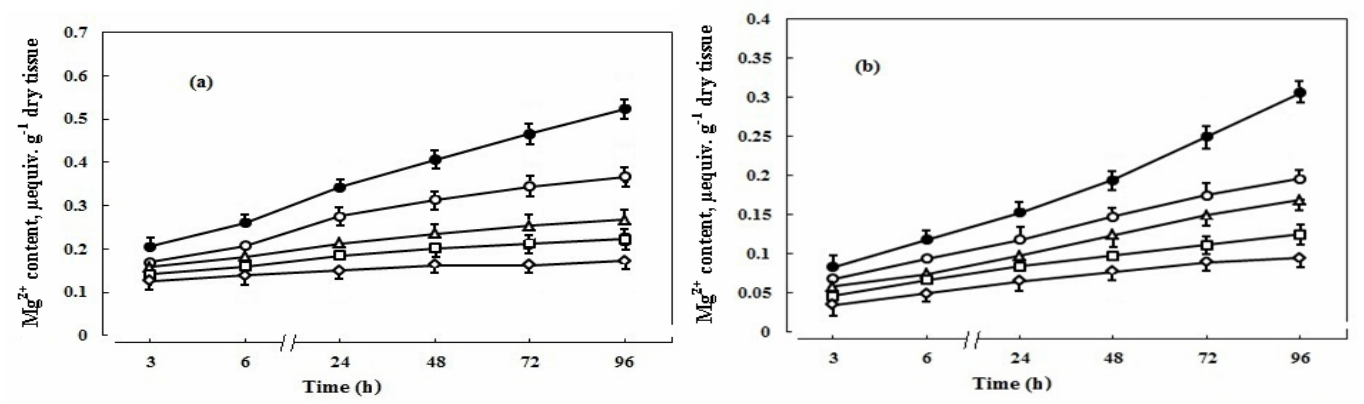

Fig. 3. The effect of different concentrations of aluminium on the accumulation of $\mathrm{Mg}^{2+}$ in the (a) root and (b) shoot of rice seedlings grown in solution culture. Otherwise as Fig. 1.

In chickpea seedlings, the reduction in $\mathrm{Mg}^{2+}$ accumulation in the root, stem and leaves gradually increased with the increase in $\mathrm{Al}$ concentration from 10 to $150 \mu \mathrm{M}$ (Figs 4a-c). Similarly, $\mathrm{Al}$ decreased $\mathrm{Mg}^{2+}$ accumulation in cabbage, lettuce and kikuya grass (Huett and Menary 1980). 

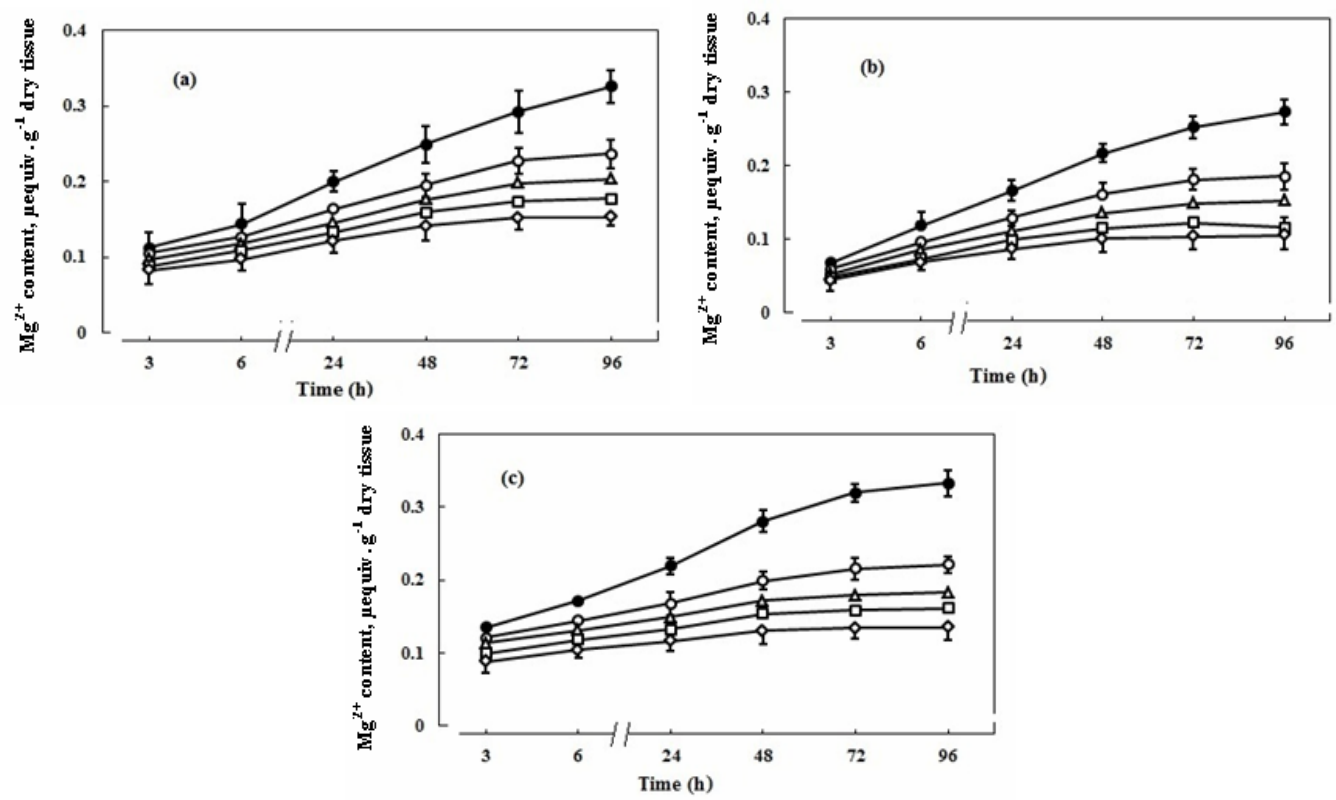

Fig. 4. The effect of different concentrations of aluminium on the accumulation of $\mathrm{Mg}^{2+}$ in the (a) root, (b) stem and (c) leaves of chickpea seedlings grown in solution culture. Otherwise as Fig. 1.

$\mathrm{Al}(10-150 \mu \mathrm{M})$ decreased $\mathrm{Fe}^{2+}$ accumulation in the root of rice except an initial stimulation. In the root, $50 \mu \mathrm{M} \mathrm{Al}$ decreased $\mathrm{Fe}^{2+}$ content by 11.0 to $20.9 \%$ from 48 to $96 \mathrm{hrs}$ of treatment (Fig. 5a). $100 \mu \mathrm{M} \mathrm{Al}$ decreased $\mathrm{Fe}^{2+}$ content in the shoot of rice by 9.9 to $13.0 \%$ from 48 to $96 \mathrm{hrs}$ of treatment (Fig. 5b). In chickpea seedlings, $150 \mu \mathrm{M}$ Al caused a 31.8 to $19.7 \%$ stimulation of $\mathrm{Fe}^{2+}$ content from 3 to $24 \mathrm{hrs}$ followed by a decrease by 9.0 to $32.0 \%$ from 48 to $96 \mathrm{hrs}$ of application (Fig. 6a). Al (10 to $150 \mu \mathrm{M})$ stimulated $\mathrm{Fe}^{2+}$ accumulation in the stem of chickpea seedlings from 3 to $48 \mathrm{hrs}$ of treatment. After a stimulation of that period the treatment showed inhibition from 72 to $96 \mathrm{hrs}$ (Fig. 6b). In the leaves of chickpea, Al caused an inhibition of $\mathrm{Fe}^{2+}$ except an initial stimulation (Fig. 6c). This result is supported by Simon and coworkers (1994) who found that Al decreased $\mathrm{Fe}^{2+}$ content in the root, stem and leaves of tomato.
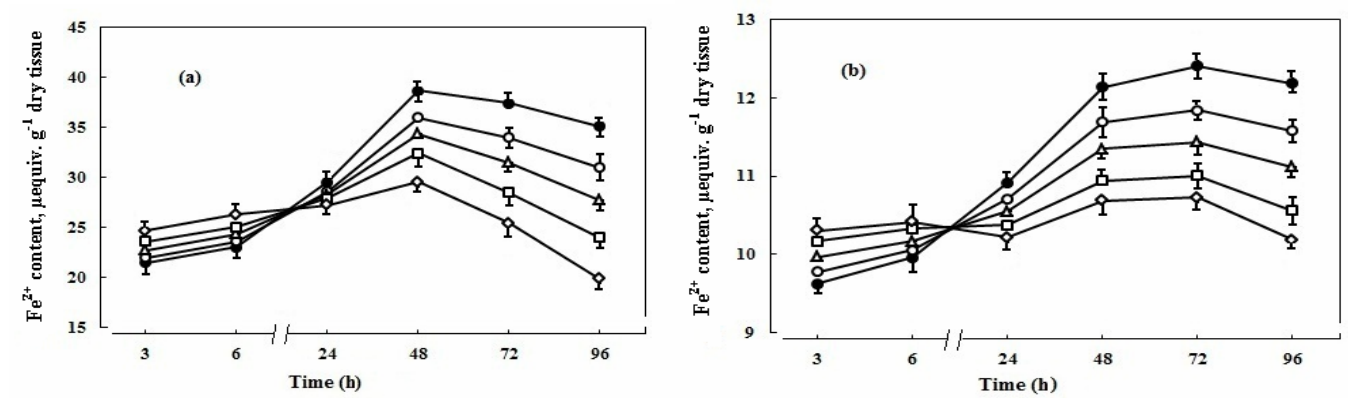

Fig. 5. The effect of different concentrations of aluminium on the accumulation of $\mathrm{Fe}^{2+}$ in the (a) root and (b) shoot of rice seedlings grown in solution culture. Otherwise as Fig. 1. 

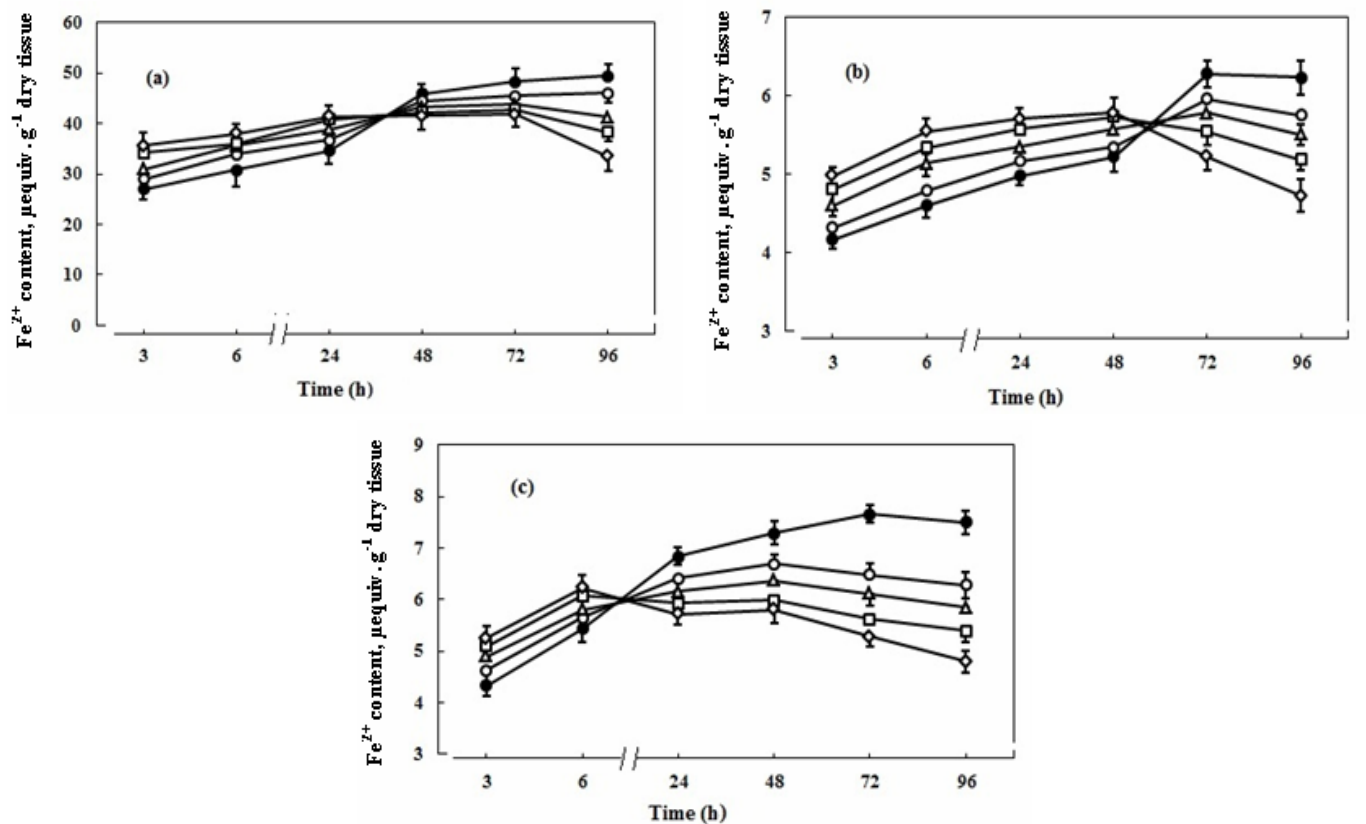

Fig. 6. The effect of different concentrations of aluminium on the accumulation of $\mathrm{Fe}^{2+}$ in the (a) root,

(b) stem and (c) leaves of chickpea seedlings grown in solution culture. Otherwise as Fig. 1.

Aluminium $(50 \mu \mathrm{M})$ increased $\mathrm{Al}^{3+}$ content in the root by 2- to 3.5-fold from 3 to $96 \mathrm{hrs}$ of exposure (Fig. 7a). In the shoot of rice seedlings, $10 \mu \mathrm{M}$ Al caused a 1.8 to 2-folds increase in $\mathrm{Al}^{3+}$ content from 3 to $72 \mathrm{hrs}$ of application and the stimulatory effect was sustained up to $96 \mathrm{hrs}$ of treatment (Fig. 7b).
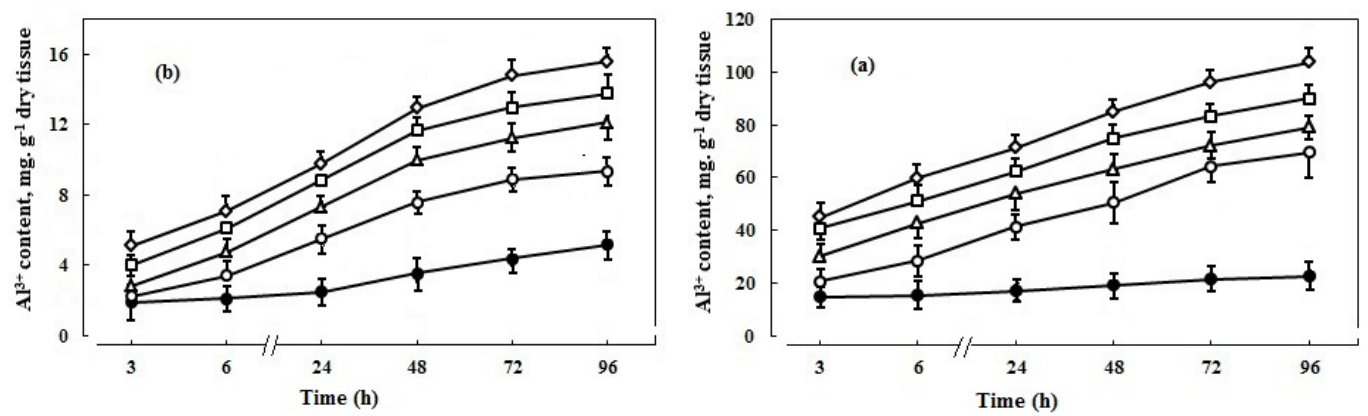

Fig. 7. The effect of different concentrations of aluminium on the accumulation of $\mathrm{Al}^{3+}$ in the (a) root and (b) shoot of rice seedlings grown in solution culture. Otherwise as Fig. 1.

In chickpea seedlings, $100 \mu \mathrm{M} \mathrm{Al}$ increased the accumulation of $\mathrm{Al}^{3+}$ in the root by 2.2 to $3-$ folds from 3 to $96 \mathrm{hrs}$ of treatment (Fig. 8a). The accumulation of $\mathrm{Al}^{3+}$ in the stem and leaves also increased with the increase in aluminium concentration from 10 to $150 \mu \mathrm{M}$ (Figs 8b, c). Similarly, $\mathrm{Al}$ application caused a 3-folds increase in $\mathrm{Al}^{3+}$ in the root of maize (Lidon et al. 2000). Application of $\mathrm{Al}$ increased accumulation of $\mathrm{Al}^{3+}$ in seedlings of tertiary buckwheat (Wang et al. 2015). 

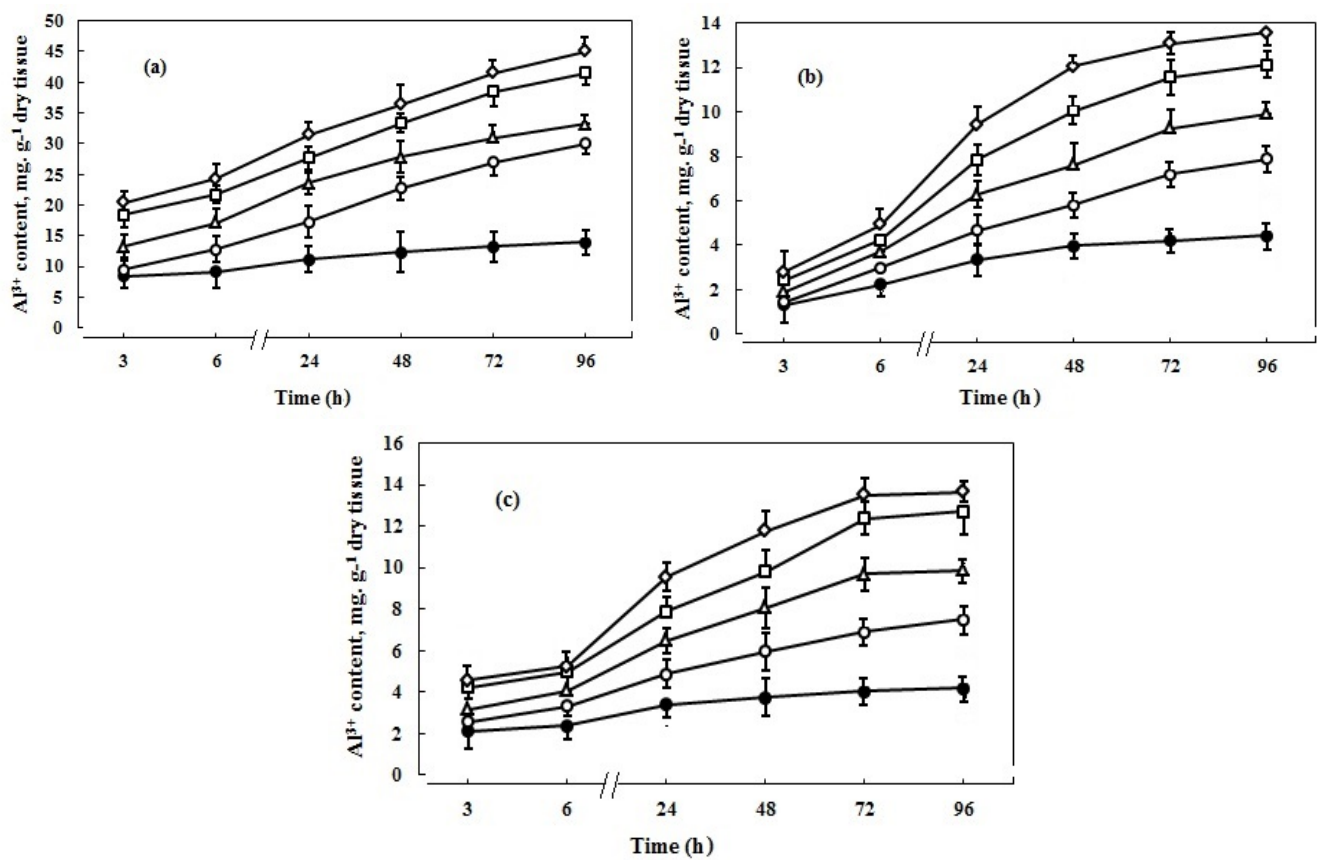

Fig. 8. The effect of different concentrations of aluminium on the accumulation of $\mathrm{Al}^{3+}$ in the (a) root, (b) stem and (c) leaves of chickpea seedlings grown in solution culture. Otherwise as Fig. 1.

A maximum of 20.0 to $57.0 \%$ inhibition of phosphate accumulation in the root of rice was recorded under the influence of $150 \mu \mathrm{M} \mathrm{Al}$ from 3 to $96 \mathrm{hrs}$ of application (Fig. 9a). At a concentration of $50 \mu \mathrm{M}$, aluminium decreased phosphate accumulation in the shoot of rice by 8.0 to $22.0 \%$ from 3 to $96 \mathrm{~h}$ of treatment (Fig. $9 \mathrm{~b}$ ). In the root of chickpea seedlings, 10 to $150 \mu \mathrm{M} \mathrm{Al}$ treatment caused an increase in phosphate accumulation from 3 to $24 \mathrm{hrs}$ followed by an inhibition of that from 48 to $96 \mathrm{hrs}$ of treatment. $100 \mu \mathrm{M} \mathrm{Al}$ caused a 28.5 to $36.0 \%$ increase in phosphate accumulation from 3 to $24 \mathrm{hrs}$ of treatment and it gradually decreased that from 12.0 to $26.0 \%$ from 48 to $96 \mathrm{hrs}$ of application (Fig. 10a). Al $(10 \mu \mathrm{M})$ inhibited phosphate accumulation in the stem of chickpea seedlings from 12.0 to $27.6 \%$ from 24 to $96 \mathrm{hrs}$ of treatment except an initial
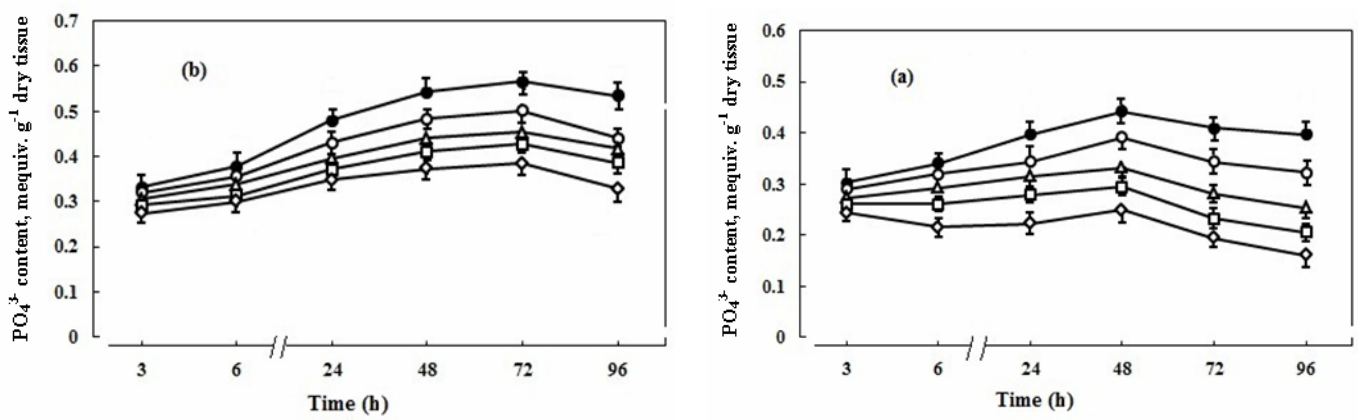

Fig. 9. The effect of different concentrations of aluminium on the accumulation of $\mathrm{PO}_{4}{ }^{3-}$ in the (a) root and (b) shoot of rice seedlings grown in solution culture. Otherwise as Fig. 1. 
stimulation at 3 to $6 \mathrm{hrs}$ of exposure. This trend of effect exerted by Al was maintained following 50, 100 and $150 \mu \mathrm{M} \mathrm{Al}$ application (Fig. 10b). The maximum inhibition of phosphate was observed in the leaves of chickpea seedlings exposed to $150 \mu \mathrm{M}$ Al which ranged from 26.8 to $57.5 \%$ from 3 to $96 \mathrm{hrs}$ of application (Fig. 10c). Similarly Al inhibited the concentration of phosphate in wheat (Foy and Flemming 1982).
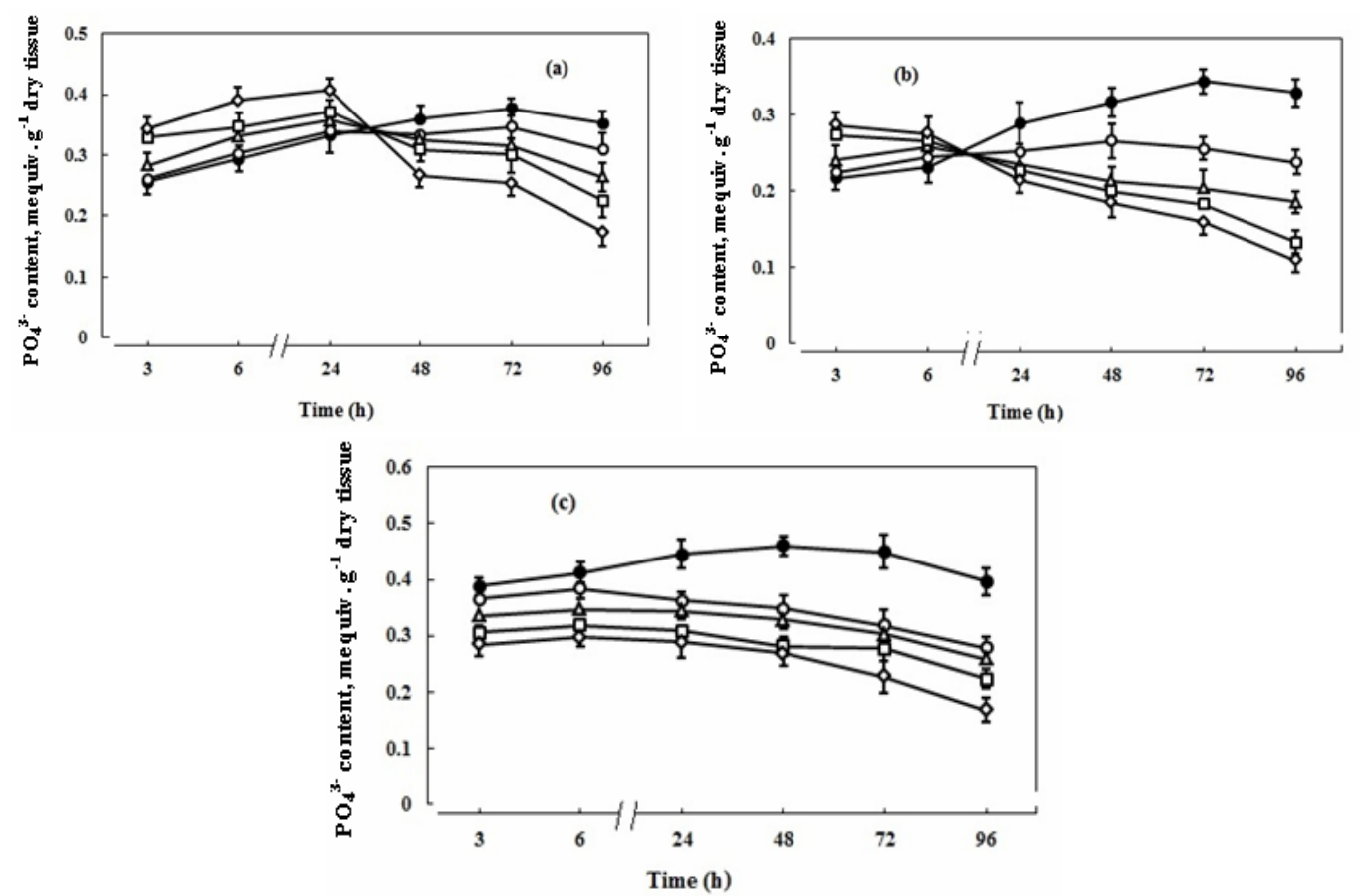

Fig. 10. The effect of different concentrations of aluminium on the accumulation of $\mathrm{PO}_{4}{ }^{3-}$ in the (a) root, (b) stem and (c) leaves of chickpea seedlings grown in solution culture. Otherwise as Fig. 1.

Al-induced inhibition of $\mathrm{Ca}$ and $\mathrm{Mg}$ in rice and chickpea seedlings aggravated the aluminium stress. The inhibition of $\mathrm{Ca}^{2+}$ accumulation might impair the permeability characteristic of plasmamembrane because $\mathrm{Ca}^{2+}$ is responsible for maintaining this unique characteristic of plasmamembrane. $\mathrm{Mg}^{2+}$ is a constituent of chlorophyll. So, Al-induced decrease in $\mathrm{Mg}^{2+}$ accumulation would decrease chlorophyll synthesis. Al stress caused inhibition in $\mathrm{Fe}^{2+}$ accumulation would reduce respiration resulting in a decrease in ion transport which is dependent on respiratory energy. The dramatic increase in the concentration of $\mathrm{Al}^{3+}$ in the root tissue would hinder the absorption of ions.

\section{References}

Bojarczuk K, Oleksyn J, Karolewski P and Żytkowiak R 2006. Response of silver birch (Betula pendula Roth.). Seedlings to experimental variation in aluminium concentration. Polish J. Ecol. 54: 189-200.

Clark RB, Pier HA, Knudsen D and Maranville JW 1981. Effect of trace element deficiencies and excesses on mineral nutrients in sorghum. J. Plant Nutr. 3: 357-374.

Façanha AR and Okorokova-Façanha AL 2002. Inhibition of phosphate uptake in corn roots by aluminumfluoride complexes. Plant Physiol. 129: 1763-1772. 
Foy CD and Fleming AL 1982. Aluminium tolerance of two wheat cultivars related to nitrate reductase activities. J. Plant. Nutr. 5: 1313-1333.

Hoagland DR and Arnon DI 1950. The water culture method for growing plants without soils. Berkeley: California Agricultural Experimental Station, pp. 347.

Huett DO and Menary RC 1980. Aluminium distribution in freeze-dried roots of cabbage, lettuce and kikuyu grass by energy dispersive X-ray analysis, Aust. J. Plant Physiol. 7: 101-111.

Jackson ML 1967. Soil Chemical Analysis. Prentice Hall of India Pvt. Ltd., New Delhi, pp. 205.

Karimaei M and Poozesh V 2016. Effects of aluminium toxicity on plant height, total chlorophyll (chl. a+b), potassium and calcium contents in spinach (Spinacia oleracea L.). Int. J. Farm. Allied Sci. 5: 76-82.

Lidon FC and Barreiro MG 2002. An overview into aluminium toxicity in maize. Bulgarian J. Plant Physiol. 28: $96-112$.

Lidon FC, Azinheira HG and Barreiro MG 2000. Aluminium toxicity in maize: biomass production and nutrient uptake and translocation. J. Plant. Nutr. 23: 151-160.

Lidon FC, Barreiro MG, Ramalho JC and Lauriano JA 1999. Effects of Al toxicity on nutrient accumulation in maize shoots: Implications on photosynthesis. J. Plant Nutr. 22: 397-416.

Ma J, Hiradate S and Matsumoto H. 1998. High aluminium resistance in buckwheat: II. Oxalic acid detoxifies aluminum internally. Plant Physiol. 117: 753-759.

May HM and Nordstrom DK 1991. Assessing the solubilities and reactions kinetics of aluminuous mineral in soils. In: Soil Acidity, Ulrich B and Summer ME (Eds), pp. 125-148, Springer, Berlin, Germany.

Ribeiro MAQ, de Almeida AAF, Mielke MS, Gomes FP, Pires MV and Baligar VC 2013. Aluminium effects on growth, photosynthesis and mineral nutrition of cacao genotypes. J. Plant Nutr. 36: 1161-1179.

Samad R and Karmoker JL 2013. Effects of $\mathrm{NaCl}$ salinity stress on accumulation of $\mathrm{K}^{+}, \mathrm{Na}^{+}, \mathrm{Cl}^{-}, \mathrm{NO}_{3}{ }^{-}$, sugar and proline contents in the seedlings of Triticale-I. Bangladesh J. Bot. 42: 189-194.

Silva S 2012. Aluminium toxicity targets in plants. J. Bot. 2012: 535-545.

Simon L, Smalley TJ, Jones JB and Lasseigne FT 1994. Aluminium toxicity in tomato .1. growth and mineral-nutrition. J. Plant Nutr. 17: 293-306.

Steiner F, Zoz T, Junior ASP, Castagnara DD and Dranski JAL 2012. Effects of aluminium on plant growth and nutrient uptake in young physic nut plants. Semina: Ciências Agrárias, Londrina 33: 1779-1788.

Wagatsuma T, Kaneko M and Hayasaka Y 1987. Destruction process of plant root cells by aluminium. Soil. Sci. Plant Nutr. 33: 161-175.

Wang H, Chen RF, Iwashita T, Shen RF and Ma JF 2015. Physiological characterization of aluminium tolerance and accumulation in tartary and wild buckwheat. New Phytol. 205: 273-279.

Zhang Z, Liao H and Lucas WJ 2014. Molecular mechanisms underlying phosphate sensing, signaling, and adaptation in plants. J. Integrative Plant Biology. 56: 192-220.

Zheng SJ 2010. Crop production on acidic soils: overcoming aluminium toxicity and phosphorus deficiency. Ann. Bot. 106: 183-184.

Zheng SJ, Yang JL, He YF, Zhanh L, You JF, Shen RF and Matsumoto H 2005. Immobilization of aluminium with phosphorus in roots is associated with high aluminium resistance in buckwheat. Plant Physiol. 138: 297-303. 